Research Paper

\title{
Melissa Officinalis L. Extracts Protect Human Retinal Pigment Epithelial Cells against Oxidative Stress- Induced Apoptosis
}

\author{
In Cheul Jeung, ${ }^{1,2}$, Donghyun Jee ${ }^{3}$, Chang-Rae Rho ${ }^{1,3}$, Seungbum Kang ${ }^{1,3 凶}$ \\ 1. Clinical Research Institute, Daejeon St. Mary's Hospital, College of Medicine, The Catholic University of Korea, Daejeon 301-012, Republic of Korea; \\ 2. Department of Obstetrics and Gynecology, College of Medicine, The Catholic University of Korea, Seoul, 137-701, Republic of Korea \\ 3. Department of Ophthalmology and Visual Science, College of Medicine, The Catholic University of Korea, Seoul, 137-701, Republic of Korea.
}

$\square$ Corresponding author: Seungbum Kang MD, PhD. Department of Ophthalmology and Visual Science, Daejeon St. Mary's Hospital, College of Medicine, The Catholic University of Korea, 64 Daeheung-ro, Jung-gu, Daejeon, 301-012, Republic of Korea. Tel.: +82 42220 9126; fax: +82 42 220 9126; E-mail: john0730@catholic.ac.kr.

() Ivyspring International Publisher. Reproduction is permitted for personal, noncommercial use, provided that the article is in whole, unmodified, and properly cited. See http://ivyspring.com/terms for terms and conditions.

Received: 2015.09.15; Accepted: 2015.12.10; Published: 2016.02.03

\begin{abstract}
Background: We evaluated the protective effect of ALS-L1023, an extract of Melissa officinalis L. (Labiatae; lemon balm) against oxidative stress-induced apoptosis in human retinal pigment epithelial cells (ARPE-19 cells).

Methods: ARPE- 19 cells were incubated with ALS-L1023 for $24 \mathrm{~h}$ and then treated with hydrogen peroxide $\left(\mathrm{H}_{2} \mathrm{O}_{2}\right)$. Oxidative stress-induced apoptosis and intracellular generation of reactive oxygen species (ROS) were assessed by flow cytometry. Caspase-3/7 activation and cleaved poly ADP-ribose polymerase (PARP) were measured to investigate the protective role of ALS-L1023 against apoptosis. The protective effect of ALS-L1023 against oxidative stress through activation of the phosphatidylinositol 3-kinase/protein kinase B (PI3K/Akt) was evaluated by Western blot analysis.

Results: ALS-L1023 clearly reduced $\mathrm{H}_{2} \mathrm{O}_{2}$-induced cell apoptosis and intracellular production of ROS. $\mathrm{H}_{2} \mathrm{O}_{2}$-induced oxidative stress increased caspase-3/7 activity and apoptotic PARP cleavage, which were significantly inhibited by ALS-L1023. Activation of the PI3K/Akt pathway was associated with the protective effect of ALS-L1023 on ARPE-19 cells.

Conclusions: ALS-L1023 protected human RPE cells against oxidative damage. This suggests that ALS-L1023 has therapeutic potential for the prevention of dry age-related macular degeneration.
\end{abstract}

Key words: ALS-L1023, apoptosis

\section{Introduction}

Age-related macular degeneration (AMD) is one of the most common causes of irreversible visual loss among the elderly in developed countries $[1,2]$. AMD is clinically classified as exudative (wet) or non-exudative (dry) AMD. More than 90\% of AMD are non-exudative in form, for which there is no current effective treatment available [3]. Clinical features of this dry form of AMD are pigmentary changes of the retinal pigment epithelium (RPE) and accumulation of drusen between the RPE layer and Bruch's membrane. Although the exact pathogenesis of dry
AMD is still not clear, dysfunction of RPE cells leading to secondary photoreceptor loss is suggested as a pathological cause of AMD development [4].

The etiology of AMD has been attributed to multiple factors (genetic, environmental, behavioral, and nutritional). However, numerous studies have suggested that aging is the most powerful single factor affecting AMD development [5]. One of the causative factors of age-related diseases is oxidative stress, which refers to cellular damage caused by reactive oxygen species (ROS) [6]. Oxidative stress with im- 
paired free-radical scavenging has also been implicated in AMD and is known to play a significant role in the development of RPE dysfunction, degeneration, and death during aging [7]. RPE phagocytosis of the photoreceptor outer segment, light irradiation of melanin, and photoexcited pigment lipofuscin produce hydrogen peroxide $\left(\mathrm{H}_{2} \mathrm{O}_{2}\right)$, a ROS to which RPE cells are particularly vulnerable [8]. Many previous in vitro studies demonstrated that oxidative stress from $\mathrm{H}_{2} \mathrm{O}_{2}$ leads to RPE cell death by causing preferential damage to its mitochondrial DNA [8-10]. Thus, various approaches to protecting RPE cells from oxidative stress have been investigated to slow AMD progression. The protective effects of antioxidants on AMD progression are also clinically supported by epidemiological evidence from two large-scale trials: an age-related eye disease study (AREDS) and AREDS2 $[11,12]$. Daily oral supplementation with antioxidant vitamins and minerals is reportedly effective in reducing the risk of developing advanced AMD by $25 \%$ at 5 years.

Well-known antioxidants include polyphenols, which are naturally occurring compounds present mainly in plants, vegetables, and fruits. Polyphenols are a secondary metabolite of plants and are excellent antioxidants, capable of neutralizing the reactivity of ROS produced as byproducts via various metabolic pathways. Recently, their biological action as antioxidants has been widely investigated, due to their protective effects against various age-related degenerative disorders, such as cancer, cardiovascular disease, diabetes, and AMD [13-16].

The leaves of Melissa officinalis L., commonly known as lemon balm, have been used in traditional phytomedicine since ancient times, and have been prescribed for their tonic, antispasmodic, carminative, anxiolytic, sedative, mood-altering, and memory-enhancing effects [17-19]. Numerous investigations have demonstrated that this medicinal herb also has antiviral, neuroprotective, antitumoral, and antiangiogenic effects [20-23]. Recently, it was shown that extracts of $M$. officinalis $L$. exhibit antioxidant and free-radical scavenging activities [24].

However, it is not known whether M. officinalis $L$. extracts can protect human RPE cells against oxidative stress. Therefore, in the present study, we investigated the cytoprotective effect of the extract in oxidatively stressed human RPE cells, through the phosphoinositide 3-kinase (PI3K)/ Akt signaling pathway.

\section{Materials and Methods}

\section{Cell culture}

Human RPE cell line ARPE-19 was purchased from the American Type Culture Collection (Manas- sas, VA, USA). ARPE-19 cells were routinely cultured in Dulbecco's modified Eagle's Medium/Nutrient Mixture F-12 (DMEM/F12, Gibco Life Technologies, Carlsbad, CA, USA), supplemented with $10 \%$ fetal bovine serum and $1 \%$ penicillin/streptomycin in a $37^{\circ} \mathrm{C}$ incubator under a humidified atmosphere containing 5\% $\mathrm{CO}_{2}$. ARPE-19 cells within 10 passages from the time of purchase were used.

\section{Drugs}

Melissa officinalis L. leaves were purchased from Alfred Galke GmbH (Harz, Germany). M. officinalis L. extract (ALS-L1023; AngioLab Inc., Daejeon, Korea) was manufactured from the leaves of $M$. officinalis $L$. using activity-guided fractionation. Briefly, dried $M$. officinalis $L$. leaves were extracted with aqueous ethanol. The extracts were filtered and concentrated. The concentrated ethanol extract was fractionated with ethyl acetate, further concentrated, and then dried to a powder form. ALS-L1023 was then dissolved in dimethyl sulphoxide (DMSO; Sigma, St. Louis, MO, USA) for in vitro testing.

\section{Cell viability assay}

RPE cell viability was evaluated using a 3-(4,5-dimethylthiazol-2-yl)-2,5-diphenyltetrazolium bromide (MTT) assay. ARPE-19 cells were plated in 96-well microplates at a density of $1 \times 10^{5}$ cells/well. The ARPE-19 cells were then treated with different concentrations of $\mathrm{H}_{2} \mathrm{O}_{2}(0-0.5 \mathrm{mM})$ and ALS-L1023 $(6.25-200 \mu \mathrm{g} / \mathrm{mL})$. Pre-treated ARPE-19 cells with ALS-L1023 were incubated for $24 \mathrm{~h}$, followed by a 4 h-exposure of $\mathrm{H}_{2} \mathrm{O}_{2}(0.5 \mathrm{mM})$. MTT solution was added $(10 \mu \mathrm{L} /$ well $)$, and the cells were then incubated for $4 \mathrm{~h}$ at $37^{\circ} \mathrm{C}$. The absorbance was measured at 450 $\mathrm{nm}$ by a microplate reader (Model 680; Bio-Rad, Hercules, CA, USA). All experiments were performed in triplicate. In each experiment, a minimum of three wells per treatment were used. The absorbance values were expressed as a percentage of the control condition (representing 100\% cell viability). The relative cell viability was defined as the absorbance of treated wells divided by that of the control.

\section{Flow cytometry analysis for cell apoptosis}

The cytoprotective effect of ALS-L1023 was evaluated by fluorescence-activated cell sorting (FACS) using a propidium iodide (PI) solution and Annexin V. ARPE-19 cells were grown on a six-well plate at a density of $2 \times 10^{5}$ cells/well and treated with or without ALS-L1023 for $24 \mathrm{~h}$, before treatment with $0.5-\mathrm{mM} \mathrm{H}_{2} \mathrm{O}_{2}$ for $4 \mathrm{~h}$. The cells were washed twice and collected with phosphate-buffered saline (PBS). ARPE-19 cells were detached with trypsin-EDTA, resuspended in a fresh culture medium, and stained with PI and Annexin V (BD Biosciences, San Jose, CA, 
USA). Apoptotic ARPE-19 cells were sorted by FACS (BD FACSCanto II flow cytometry, BD Biosciences). PI-positive and Annexin V-positive cells were quantified after gating using forward and side scattering. The results are expressed as the percentage of Annexin V-stained cells. All experiments were performed in triplicate.

\section{Intracellular ROS measurement}

The intracellular levels of ROS were measured using ROS detection reagents (2',7'-dichlorodihydrofluorescein diacetate, $\mathrm{H}_{2} \mathrm{DCF}-\mathrm{DA}$, Invitrogen, Carlsbad, CA, USA). This measurement is based on ROS-dependent oxidation of $\mathrm{H}_{2}$ DCF-DA to 2',7'-dichlorodihydrofluorescein (DCF). ARPE-19 cells were incubated with $10 \mu \mathrm{M}$ of $\mathrm{H}_{2}$ DCF-DA for $30 \mathrm{~min}$ at $37^{\circ} \mathrm{C}$, then detached with trypsin/EDTA, washed, and re-suspended in PBS $\left(1 \times 10^{6}\right.$ cells $\left./ \mathrm{mL}\right)$. The fluorescence intensity of 10,000 cells was analyzed using flow cytometry at excitation and emission wavelengths of 488 and $525 \mathrm{~nm}$, respectively. Untreated cells served as the control. The results were expressed as the fluorescence intensity of DCF with respect to that of the control. Experiments were performed in triplicate.

\section{Caspase activity assay}

Caspase-3/7 activity was determined using an assay kit (CaspaTag Caspase-3, 7 In Situ Assay Kit, Merck KGaA, Darmstadt, Germany). ARPE-19 cells (1 $\times 10^{5}$ cells) were incubated with ALS-L1023 (100 $\mu \mathrm{g} / \mathrm{mL})$ for $24 \mathrm{~h}$, before a 4-h exposure to $\mathrm{H}_{2} \mathrm{O}_{2}(0.5$ $\mathrm{mM})$. According to the manufacturer's instruction, cells were incubated with green fluorochrome-labeled inhibitors of caspases (FLICA) (FAM-VAD-FMK) at $37^{\circ} \mathrm{C}$ for $1 \mathrm{~h}$. After washing, the fluorescence released by active caspase-3 or caspase-7 was measured in a 96-well plate, using an excitation wavelength of 490 $\mathrm{nm}$ and an emission wavelength of $520 \mathrm{~nm}$ in a fluorometric plate reader (Envision Multi-label Plate Reader; Perkin Elmer, Waltham, MA, USA). Three independent experiments were performed.

\section{Western Blot Analysis}

Standard Western blot analysis methods were used. Briefly, ARPE-19 cells were treated with or without ALS-L1023 $(100 \mu \mathrm{g} / \mathrm{mL})$, before exposure to $\mathrm{H}_{2} \mathrm{O}_{2}(0.5 \mathrm{mM})$. After $4 \mathrm{~h}$, the ARPE-19 cells were harvested and pooled in $100 \mu \mathrm{L}$ of a lysis buffer (Pro-prep Protein Extraction Solution, iNtRON Biotechnology, Korea). Cell lysates were centrifuged at $13,000 \mathrm{rpm}$ for $15 \mathrm{~min}$ at $4^{\circ} \mathrm{C}$, and the supernatants collected. After measuring the protein concentration (Bicinchoninic Acid Protein Assay Kit, Pierce, Rockford, IL, USA), equal amounts of protein were separated by electrophoresis on a $10 \%$
SDS-polyacrylamide gel and transferred electrophoretically to a nitrocellulose membrane (Bio-Rad). After blocking with a $3 \%$ bovine serum albumin solution, the membrane was incubated overnight at $4^{\circ} \mathrm{C}$. Antibodies used in the Western blot assay included an anti-PARP antibody (Cell Signaling, Danvers, MA, USA) and an anti-cleaved PARP antibody (Cell Signaling) to detect the total full-length and cleaved forms of PARP, respectively, an anti-phospho Akt antibody (Cell Signaling) and an anti Akt antibody (Cell Signaling); $\beta$-actin served as an internal control. The intensity of the signals was recorded and quantified by a molecular imaging system (Molecular Imager ChemiDoc XRS+, Bio-Rad).

\section{Statistical Analysis}

Data are presented as means \pm SD. The SPSS software package (ver. 17.0; SPSS Inc., Chicago, IL, USA) was used for statistical analysis. Statistical significance was determined using an unpaired t-test. $\mathrm{P}$ values $<0.05$ were considered statistically significant.

\section{Results}

\section{Cytotoxic effects of ALS-L1023 on RPE cells}

We first investigated the potential cytotoxicity of ALS-L1023 on human RPE cells. The viability of ARPE-19 cells was evaluated using MTT assay with different concentrations of ALS-L1023. ALS-L1023 did not affect cell viability for concentrations $>6.25-150$ $\mu \mathrm{g} / \mathrm{mL}$, as shown in Figure 1A. However, at a concentration of $200 \mu \mathrm{g} / \mathrm{mL}$, a slight decrease in cell viability was observed $(79.5 \pm 4.5 \%)$. As such, concentrations of ALS-L1023 $<150 \mu \mathrm{g} / \mathrm{mL}$ were used in the following experiments. To choose the appropriate concentration of $\mathrm{H}_{2} \mathrm{O}_{2}$, dose-response tests were performed. Figure 1B shows that cell viability decreased significantly as the concentration of $\mathrm{H}_{2} \mathrm{O}_{2}$ increased. $\mathrm{H}_{2} \mathrm{O}_{2}$ treatment using concentrations of $0.0625,0.125$, 0.25 , and $0.5 \mathrm{mM}$ resulted in $90.2 \pm 3.4 \%, 80.1 \pm 3.6 \%$, $61.2 \pm 2.9 \%$, and $28.5 \pm 4.2 \%$ cell viability, respectively. Therefore, a concentration of $0.5-\mathrm{mM} \mathrm{H}_{2} \mathrm{O}_{2}$ was used as the working concentration in the following experiments.

\section{ALS-L1 023 inhibits $\mathrm{H}_{2} \mathrm{O}_{2}$-induced RPE cell death}

Next, we investigated whether ALS-L1023 treatment could protect RPE cells from $\mathrm{H}_{2} \mathrm{O}_{2}$-induced cell death. ARPE-19 cells were incubated with ALS-L1023 for $24 \mathrm{~h}$. The medium was then removed and replaced with a fresh culture medium containing $\mathrm{H}_{2} \mathrm{O}_{2}(0.5 \mathrm{mM})$ for $4 \mathrm{~h}$. As demonstrated in Figure 2A, ALS-L1023 pretreatment prevented RPE cell death from $\mathrm{H}_{2} \mathrm{O}_{2}$-induced oxidative stress in a dose-dependent manner. The cell viability of ARPE-19 
cells at concentrations of $0,6.25,12.5,25,50,75,100$, 150 , and $200 \mu \mathrm{g} / \mathrm{mL}$ ALS-L1023 was $25.9 \pm 3.9 \%, 25.1$ $\pm 2.7 \%, 25.0 \pm 2.3 \%, 26.3 \pm 6.5 \%, 35.2 \pm 4.1 \%, 56.8 \pm$ $6.8 \%, 59.8 \pm 3.7 \%, 66.7 \pm 4.1 \%$, and $67.1 \pm 2.3 \%$, respectively. To investigate the protective effect of ALS-L1023 against $\mathrm{H}_{2} \mathrm{O}_{2}$-induced cell apoptosis, ARPE-19 cells were incubated with ALS-L1023 for 24 $\mathrm{h}$ and then exposed to $0.5-\mathrm{mM} \mathrm{H}_{2} \mathrm{O}_{2}$ for $4 \mathrm{~h}$. The apoptosis rate was determined with flow cytometry. ALS-L1023 pretreatment $(100 \mu \mathrm{g} / \mathrm{mL})$ significantly inhibited $\mathrm{H}_{2} \mathrm{O}_{2}$-induced RPE cells apoptosis, as shown in Figure 2B. The proportions of Annexin V-positive (apoptosis) cells increased in ARPE-19 cells treated with $0.5-\mathrm{mM} \mathrm{H}_{2} \mathrm{O}_{2}$ alone, compared with the untreated control culture $(45.4 \pm 9.9 \%$ and $2.5 \pm 1.5 \%$, respectively, $P<0.05)$. The pretreatment of ARPE-19

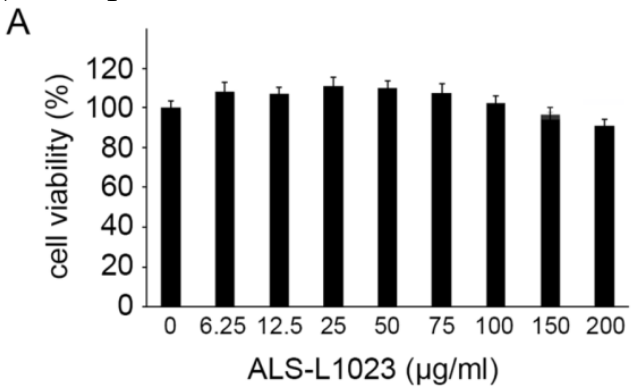

cells with ALS-L1023 before $\mathrm{H}_{2} \mathrm{O}_{2}$ exposure significantly reduced the proportion of Annexin $\mathrm{V}$-positive cells, compared with cultures treated with only $\mathrm{H}_{2} \mathrm{O}_{2}$ $(12.3 \pm 4.6 \%$ and $45.4 \pm 9.9 \%$, respectively, $P<0.05)$ (Fig. 2C).

\section{Inhibition of $\mathrm{H}_{2} \mathrm{O}_{2}$-induced intracellular ROS by ALS-L1 023}

ARPE-19 cells were incubated with ALS-L1023 $(100 \mu \mathrm{g} / \mathrm{mL})$ for $24 \mathrm{~h}$ and then treated with $\mathrm{H}_{2} \mathrm{O}_{2}(0.5$ $\mathrm{mM}$ ) for $4 \mathrm{~h}$; intracellular ROS levels were measured by DCF fluorescence. Figure $3 \mathrm{~A}$ shows that the DCF fluorescence intensity increased significantly in $\mathrm{H}_{2} \mathrm{O}_{2}$-treated cells. However, pretreatment with ALS-L1023 reduced the DCF fluorescence level $(P<$ 0.05) (Fig. 3B).

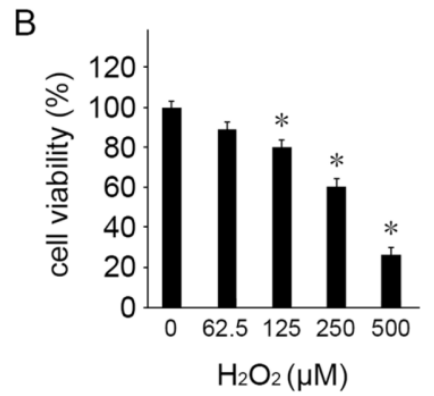

Figure 1. Cytotoxicity of Melissa officinalis L. extract (ALS-L1023) on human retinal pigment epithelial cells (ARPE-19 cells). Cell viability was determined by a 3-(4,5-dimethylthiazol-2-yl)-2,5-diphenyltetrazolium bromide assay. (A) ARPE-19 cells were treated with different concentrations of ALS-L1023 (0-200 $\mu$ g/mL). The values are expressed as a percentage of the control ( $100 \%$ cell viability). ALS-L1023 treatment had no significant effect on ARPE-19 cell viability at concentrations ranging from $6.25-200$ $\mu \mathrm{g} / \mathrm{mL}$. (B) ARPE-19 cells were treated with different concentrations of $\mathrm{H} 2 \mathrm{O} 2(0-500 \mu \mathrm{M})$. The values are expressed as a percentage of the control (100\% cell viability). $\mathrm{H} 2 \mathrm{O} 2$ treatment caused a dose-dependent decrease in ARPE- 19 cell viability at concentrations ranging from $62.5-500 \mu \mathrm{M}$. *P $<0.05$ vs. the control.

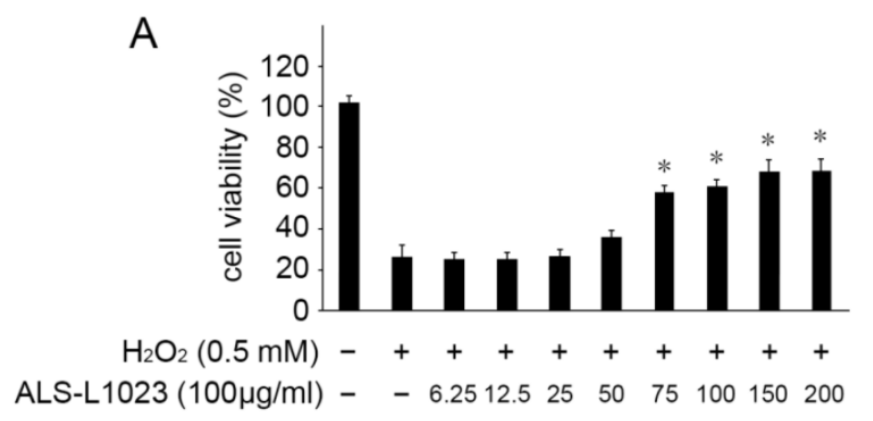

B

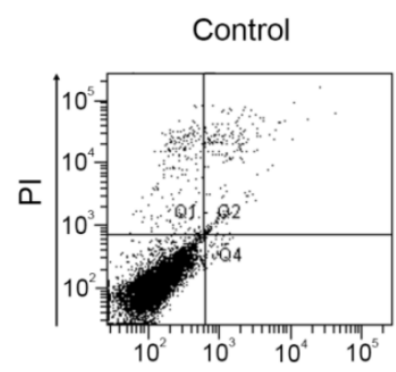

$\mathrm{H}_{2} \mathrm{O}_{2}(0.5 \mathrm{mM})$

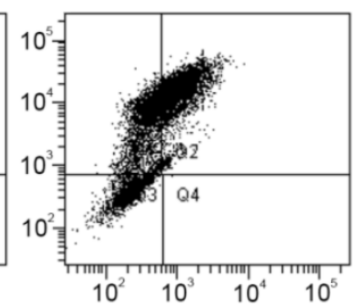

Annexin $V$
$\mathrm{H}_{2} \mathrm{O}_{2}(0.5 \mathrm{mM})+$

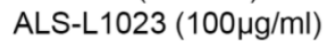

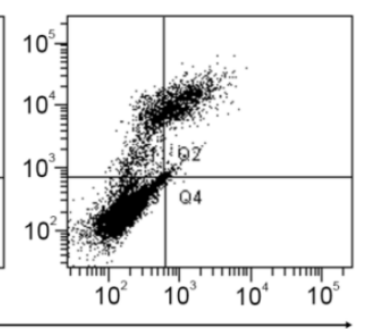

.

C

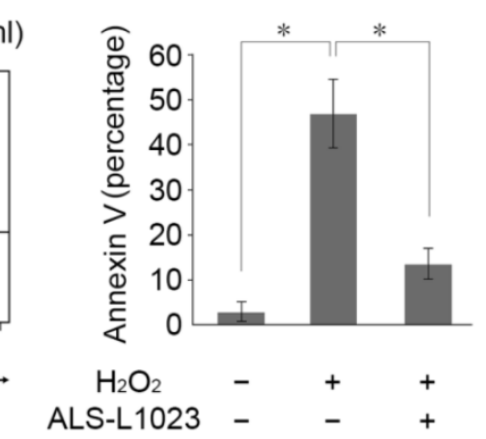

Figure 2. ALS-L1023 increased the cell viability from oxidative-induced stress. (A) ARPE-19 cells were treated with different concentrations of ALS-L1023 for $24 \mathrm{~h}$ and then exposed to $\mathrm{H} 2 \mathrm{O} 2(0.5 \mathrm{mM})$. *P $<0.05$ vs. $\mathrm{H} 2 \mathrm{O} 2$-exposed cells without ALS-L1023 pretreatment. (B) Flow cytometry showed that the apoptosis rate of ARPE-19 cells treated with ALS-L1023 $(100 \mu \mathrm{gg} / \mathrm{mL})$ was much lower than that of cells treated with H2O2 $(0.5 \mathrm{mM})$ alone. (C) Quantification of the rate of apoptotic cells detected with flow cytometry. $* \mathrm{P}<0.05$. 


\section{Suppression of caspase-3/7 activity and PARP cleavage by ALS-L1023}

The protective mechanism of ALS-L1023, on ARPE-19 cells against oxidative stress, was assessed by investigating PARP cleavage and caspase- $3 / 7$ activity. Caspase- $3 / 7$ activity in RPE cells increased 2.9-fold relative to the control after $\mathrm{H}_{2} \mathrm{O}_{2}$ treatment. However, the increased activity of caspase- $3 / 7$ was

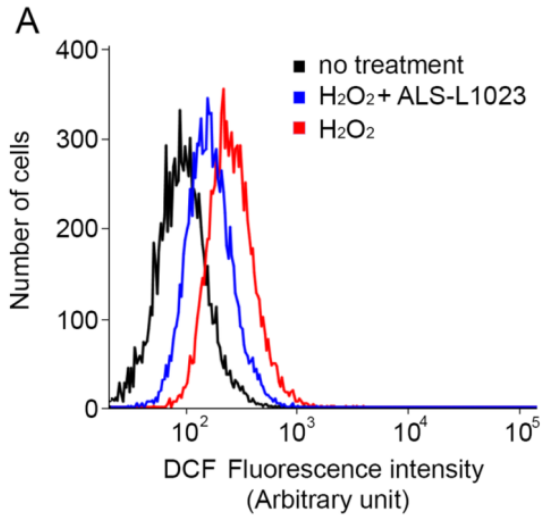

significantly inhibited by pretreatment with 100 $\mu \mathrm{g} / \mathrm{mL}$ ALS-L1023 $(P<0.05)$ (Fig. 4A). Figure 4B shows that there was a marked increase in the level of cleaved PARP in $\mathrm{H}_{2} \mathrm{O}_{2}$-treated cells compared with the control. The increase in cleaved PARP, however, was inhibited significantly by ALS-L1023 pretreatment $(100 \mu \mathrm{g} / \mathrm{mL})(P<0.05)$.

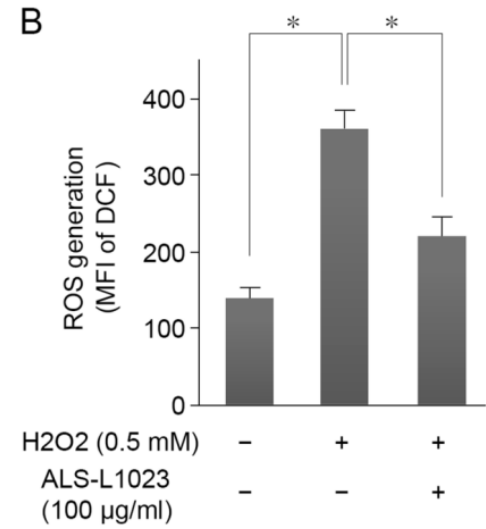

Figure 3. ALS-L1023 inhibits H2O2-induced intracellular reactive oxygen species (ROS) production. (A) ARPE- 19 cells were incubated with ALS-L1023 (100 $\mu$ g/mL) for $24 \mathrm{~h}$ and then exposed to $\mathrm{H} 2 \mathrm{O} 2(0.5 \mathrm{mM})$. The intracellular ROS was measured with flow cytometry using H2DCF-DA. (B) Mean fluorescence intensity of DCF expressed as means \pm SD. ALS-L1023 reduced the generation of ROS in ARPE- 19 cells. *P $<0.05$.

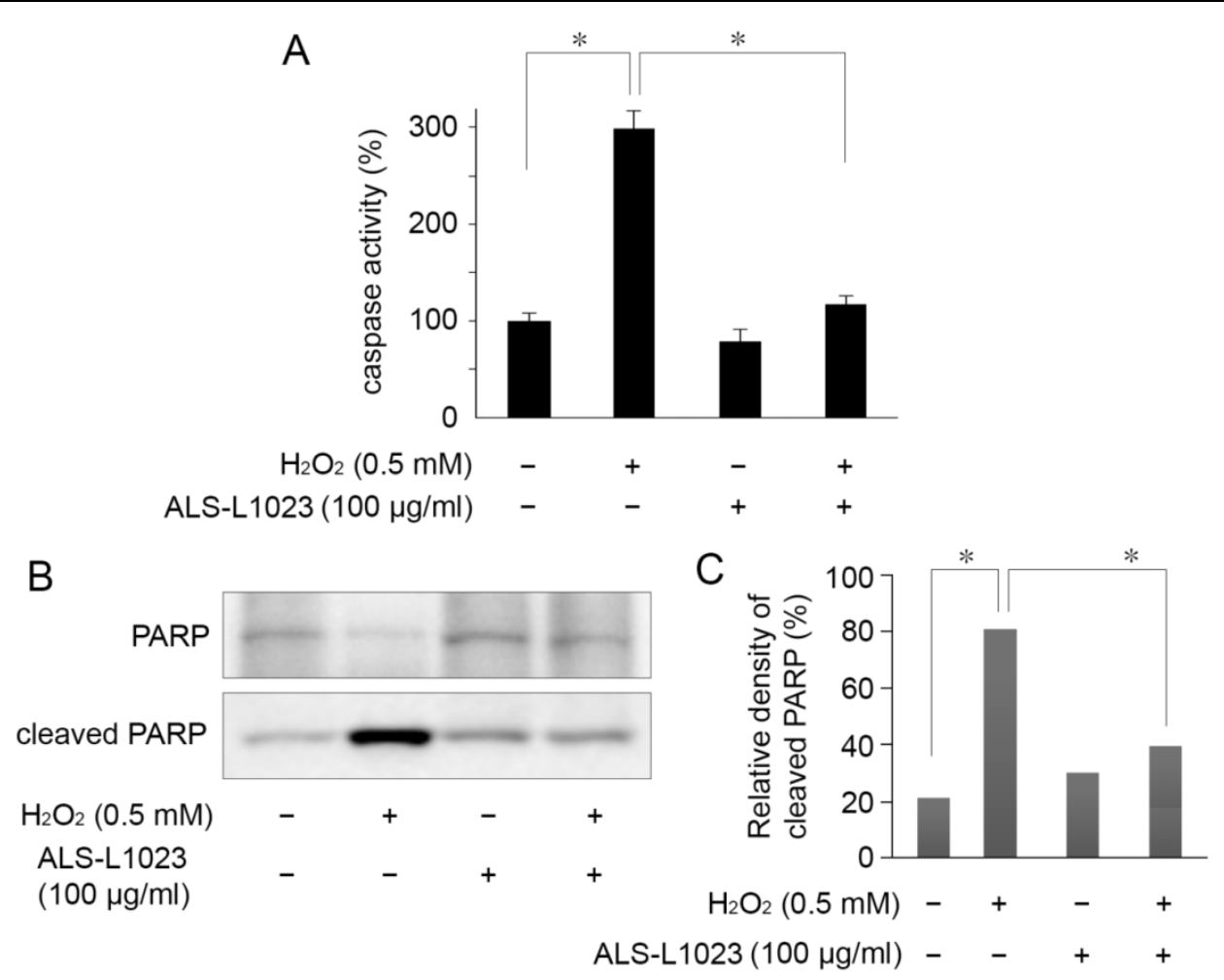

Figure 4. ALS-L1023 protects ARPE-19 cells from H2O2-induced apoptosis via inhibition of caspase-3/7 activity and poly ADP-ribose polymerase (PARP) cleavage. (A) Caspase-3/7 activity after a 4-h exposure to $\mathrm{H} 2 \mathrm{O} 2$ was determined by measuring the fluorescence level with and without ALS-L1023 (100 $\mu \mathrm{g} / \mathrm{mL})$ pretreatment. The relative levels of caspase-3/7 activity were expressed as the percentage of untreated control cells (100\%). *P< 0.05 (B) Effect of ALS-L1023 on PARP cleavage as shown by Western blot analysis. Cleaved PARP expression was elevated by H2O2 $(0.5 \mathrm{mM})$ treatment, whereas ALS-L1023- pretreatment $(100 \mu \mathrm{g} / \mathrm{mL})$ significantly inhibited PARP cleavage. (C) Immunoblotted PARP was quantified by densitometry; data are expressed as the percentage of cleaved PARP relative to the total expression of both the full-form and cleaved PARP. *P $<0.05$. 


\section{ALS-L1023 protects RPE cells by Akt phos- phorylation}

Akt activation reportedly plays a crucial role in protecting RPE cells from oxidative stress [25]. Therefore, we investigated whether or not Akt phosphorylation could be induced by ALS-L1023. Figure 5A showed that ALS-L1023 treatment $(100 \mu \mathrm{g} / \mathrm{mL})$ significantly increased Akt phosphorylation in ARPE-19 cells, whereas $\mathrm{H}_{2} \mathrm{O}_{2}$ treatment did not.

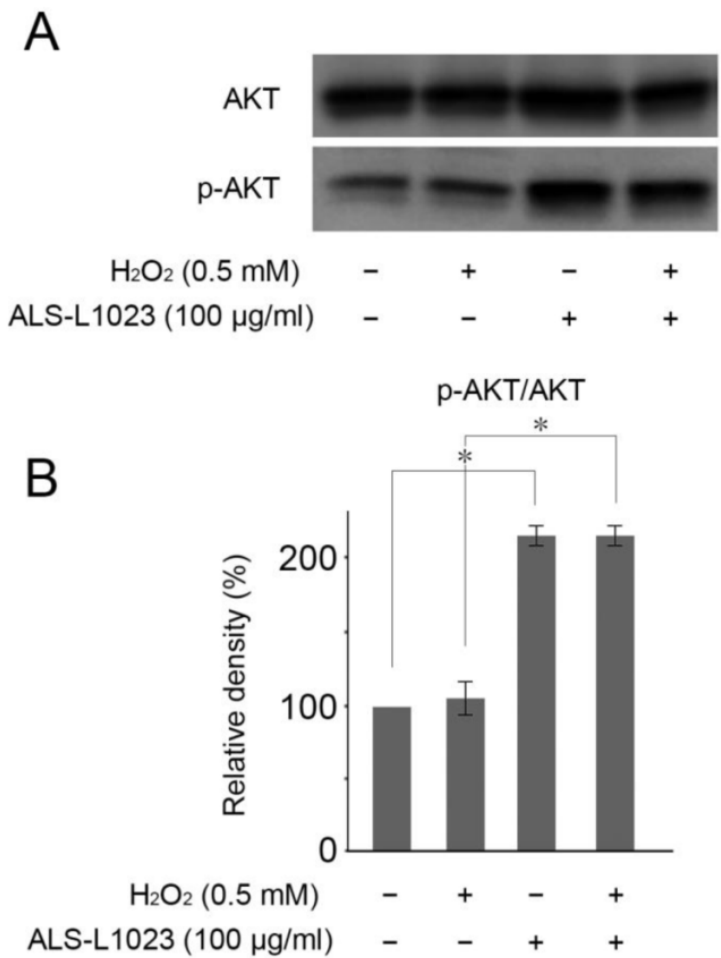

Figure 5. ALS-L1023 activates the PI3K/Akt pathway. (A) ARPE-19 cells that were pre-incubated with and without ALS-L1023 $(100 \mu \mathrm{g} / \mathrm{mL})$ were exposed to $\mathrm{H} 2 \mathrm{O} 2(0.5$ $\mathrm{mM}$ ) for $4 \mathrm{~h}$. Western blot analysis was used to measure the expressions of phosphorylated Akt and Akt. (B) Quantitative analysis was performed by measuring the relative expression level of phosphorylated $A k t$ to $A k t$. The relative expression level of the control was normalized to $100 \%$. $* \mathrm{P}<0.05$.

\section{Discussion}

In the present study, we evaluated the capacity of $M$. officinalis $L$. extract to prevent oxidative stress-induced cell death. MTT assay and flow cytometry demonstrated that pretreatment of RPE cells with ALS-L1023 significantly increased cell viability and reduced the apoptosis from oxidative stress. The protection against oxidative stress was mediated by the inhibition of caspase-3, 7 activity and PARP cleavage, which are known to be strong stimulators of apoptosis. The pretreatment of ALS-L1023 generated less intracellular ROS. This protective effect of ALS-L1023 was mediated through the Akt signal transduction pathway. Taken together, M. officinalis $L$. extract effectively protects human RPE cells from
$\mathrm{H}_{2} \mathrm{O}_{2}$-induced oxidative stress via anti-apoptotic and antioxidant effects.

Polyphenols are natural plant products found mainly in fruits, vegetables, and plant-based beverages such as wine and tea. The beneficial, antioxidant effects of dietary plant polyphenols have been widely investigated. Epidemiological studies and associated meta-analyses have repeatedly reported that high dietary intake of polyphenols is associated with a decreased risk of developing various chronic diseases, including cardiovascular disease, specific forms of cancer, diabetes, osteoporosis, and neurodegenerative diseases [26-29]. The exact mechanism underlying these effects has not yet been fully elucidated. However, the radical scavenging effects of polyphenols are accepted as an active mechanism for decreasing oxidative stress [30, 31]. Polyphenols may also be involved in cellular signaling pathways; for example, mitogen-activated protein kinase and PI3K/Akt signaling cascades may influence cellular processes involved in the initiation and progression of cancer, cardiovascular diseases, and neurodegeneration [32].

Using a b-carotene-linoleic acid bleaching assay, M. officinalis L. extract showed exceptionally high antioxidant activity. This extract is capable of scavenging a wide range of synthetic and naturally occurring free radicals. Its in vitro antioxidative activity was superior to that of gallic and caffeic acids, and was as potent as quercetin and butylated hydroxyanisole [33]. Compositional fingerprint analysis revealed that $M$. officinalis $L$. contains a variety of polyphenolic compounds, primarily phenolic acid with hydroxycinnamic acid derivatives and flavonoid with caffeic acid, m-coumaric acid, eriodictyol-7-O-glucoside, naringin, hesperidin, rosmarinic acid, naringenin, and hesperetin [33]. The primary substances present in ALS-L1023, flavonoids and hydroxycinnamic acid derivatives possess antioxidant activity; thus, they also contribute to the antioxidant properties of the extract.

The AREDS and AREDS2 formula used to prevent the progression of dry AMD consists basically of antioxidants, including vitamins $\mathrm{C}$ and $\mathrm{E}$, zinc, copper, b-carotene, lutein, and zeaxanthin. Zinc and copper are cofactors of superoxide dismutase, which is among the endogenous antioxidant enzymes. A deficiency of copper or zinc increases the activity of the cytochrome P450, and thus enhances ROS generation [34]. Vitamins C and E, lutein, and zeaxanthin contribute to ROS inactivation by scavenging them. Flavonoids and hydroxycinnamic acid derivatives in Melissa officinalis $L$. extract are also believed to be scavengers of ROS [31]. Figure 3 shows that ALS-L1023 generated less intracellular ROS in human RPE cells; this promotes the usage of M. officinalis $L$. as 
a potential therapeutic herb or functional food for dry AMD.

Interestingly, M. officinalis $L$. extract reportedly has an antiangiogenic effect. Previous studies using an animal model for wet AMD showed that systemic administration of the extract inhibited choroidal neovascularization formation by suppressing the expression of vascular endothelial growth factor and matrix metalloproteinase-9 via its antioxidant activity [23]. In clinical practice, these effects have the potential to not only prevent the development of dry AMD, but also to prevent conversion from dry to wet AMD.

The Akt signaling pathway is known to be among the most critical pathways in regulating cell survival and metabolism [35]. The activation of Akt promotes cellular survival signals that can block apoptosis or withstand apoptotic stimuli. Akt phosphorylates Bcl-2-associated death promoter (BAD), which is a pro-apoptotic protein of the Bcl-2 family. Once phosphorylated, BAD is released from the Bcl-2/Bcl-X complex, which causes it to lose its pro-apoptotic function. It has been reported that the protective effect against oxidative stress-induced apoptosis in human RPE cells is strongly related to the activation of $\mathrm{PI} 3 \mathrm{~K} / \mathrm{Akt}$ [36]. In the present study, phosphorylated Akt did not increase in $\mathrm{H}_{2} \mathrm{O}_{2}$-exposed RPE cells, whereas ALS-L1023 treatment significantly enhanced Akt phosphorylation. These results suggest that ALS-L1023 may act as a survival signal through the PI3K/Akt signaling pathway; however, additional studies are required to validate this.

In summary, the present study provided evidence that the extract of M. officials L., ALS-L1023, protects human RPE cells from oxidative stress-induced cell death, which is associated with the suppression of caspase-3/7 activity, ROS generation, PARP cleavage and activation of PI3K/Akt pathways. Therefore, M. officinalis $L$. can be considered as a potential, naturally sourced, therapeutic antioxidant for the prevention of dry AMD.

\section{Acknowledgement}

This study was supported by Clinical Research Institute grant funded by the Catholic University of Korea, Daejeon St. Mary's Hospital (CMCDJ-P-2013-024) and by the Korea Health Industry Development Institute (5-2013-A0094-00030).

\section{Competing Interests}

None of the author has any financial interest in any of the products described.

The authors have declared that no competing interest exists.

\section{References}

1. Klein R, Klein BE, Linton KL. Prevalence of age related maculopathy. The Beaver Dam Eye Study. Ophthalmology 1992; 99:933-43.

2. Hawkins BS, Bird A, Klein R, West SK. Epidemiology of age-related macular degeneration. Mol Vis 1999; 5:26.

3. Klein R, Peto T, Bird A, Vannewkirk MR. The epidemiology of age-related macular degeneration. Am J Ophthalmol 2004; 137:486-95.

4. Nowak JZ. Age-related macular degeneration (AMD): pathogenesis and therapy. Pharmacol Rep 2006: 58:353-63.

5. Ambati J, Ambati BK, Yoo SH, Ianchulev S, Adamis AP. Age-related macular degeneration: etiology, pathogenesis, and therapeutic strategies. Surv Ophthalmol 2003; 48:257-93.

6. Harman D. Free radical theory of aging: an update: increasing the functional life span. Ann N Y Acad Sci 2006; 1067:10-21.

7. Beatty S, Koh H, Phil M, Henson D, Boulton M. The role of oxidative stress in the pathogenesis of age-related macular degeneration. Surv Ophthalmol 2000; 45:115-34.

8. Cai J, Wu M, Nelson KC, Sternberg P Jr, Jones DP. Oxidant-induced apoptosis in cultured human retinal pigment epithelial cells. Invest Ophthalmol Vis Sci 1999; 40:959-66

9. Cai J, Wu M, Nelson KC, Sternberg P Jr, Jones DP. Hydrogen Peroxide Causes Significant Mitochondrial DNA Damage in Human RPE Cells. Exp Eye Res 1999: 68:765-72

10. Liang FQ, Godley BF. Oxidative stress-induced mitochondrial DNA damage in human retinal pigment epithelial cells: a possible mechanism for RPE aging and age-related macular degeneration. Exp Eye Res 2003; 76:397-403.

11. Age-Related Eye Disease Study Research Group. A randomized, placebo-controlled, clinical trial of high-dose supplementation with vitamins $C$ and $\mathrm{E}$, beta carotene, and zinc for age-related macular degeneration and vision loss: AREDS report no. 8. Arch Ophthalmol 2001; 119:1417-36.

12. Age-Related Eye Disease Study 2 Research Group. Lutein + zeaxanthin and omega-3 fatty acids for age-related macular degeneration: the Age-Related Eye Disease Study 2 (AREDS2) randomized clinical trial. JAMA 2013 309.2005-15.

13. García-Lafuente A, Guillamón E, Villares A, Rostagno MA, Martínez JA. Flavonoids as anti-inflammatory agents: implications in cancer and cardiovascular disease. Inflamm Res 2009; 58:537-52

14. Peters U, Poole C, Arab L. Does tea affect cardiovascular disease? A meta-analysis. Am J Epidemiol 2001; 154:495-503.

15. Matsui T, Ebuchi S, Kobayashi M, Fukui K, Sugita K, Terahara N, et al. Anti-hyperglycemic effect of diacylated anthocyanin derived from Ipomoea batatas cultivar Ayamurasaki can be achieved through the alpha-glucosidase inhibitory action. J Agric Food Chem 2002; 50:7244-8.

16. Dugas B, Charbonnier S. Baarine M. Effects of oxysterols on cell viability, inflammatory cytokines, VEGF, and reactive oxygen species production on human retinal cells: cytoprotective effects and prevention of VEGF secretion by resveratrol. Eur I Nutr 2010; 49:435-46.

17. Kennedy DO, Little W, Haskell CF, Scholey AB. Anxiolytic effects of a combination of Melissa officinalis and Valeriana officinalis during laboratory induced stress. Phytother Res 2006; 20:96-102.

18. Kennedy DO, Scholey AB, Tildesley NT, Perry EK, Wesnes KA. Modulation of mood and cognitive performance following acute administration of Melissa officinalis (lemon balm). Pharmacol Biochem Behav 2002; 72:953-64.

19. Soulimani R, Fleurentin J, Mortier F, Misslin R, Derrieu G, Pelt JM. Neurotropic action of the hydroalcoholic extract of Melissa officinalis in the mouse. Planta Med 1991; 57:105-9.

20. Allahverdiyev A, Duran N, Ozguven M, Koltas S. Antiviral activity of the volatile oils of Melissa officinalis L. against Herpes simplex virus type-2. Phytomedicine 2004; 11:657-61.

21. López V, Martín S, Gómez-Serranillos MP, Carretero ME, Jäger AK, Calvo MI. Neuroprotective and neurological properties of Melissa officinalis. Neurochem Res 2009; 34:1955-61.

22. de Sousa AC, Alviano DS, Blank AF, Alves PB, Alviano CS, Gattass CR. Melissa officinalis L. essential oil: antitumoral and antioxidant activities. I Pharm Pharmacol 2004; 56:677-81.

23. Lee EK, Kim YJ, Kim JY, Song HB, Yu HG. Melissa officinalis extract inhibits laser-induced choroidal neovascularization in a rat model. PLoS One 2014; 9:e110109.

24. Pereira RP, Fachinetto R, de Souza Prestes A, Puntel RL, Santos da Silva GN, Heinzmann BM, et al. Antioxidant effects of different extracts from Melissa officinalis, Matricaria recutita and Cymbopogon citratus. Neurochem Res 2009. 34:973-83.

25. Yang P, Peairs JJ, Tano R, Jaffe GJ. Oxidant-mediated Akt activation in human RPE cells. Invest Ophthalmol Vis Sci 2006; 47:4598-606.

26. Scalbert A, Manach C, Morand C, Remesy C. Dietary polyphenols and the prevention of diseases. Crit Rev Food Sci Nutr 2005; 45:287-306.

27. Arts ICW, Hollman PCH. Polyphenols and disease risk in epidemiologic studies. Am J Clin Nutr 2005; 81:317-25.

28. Pandey KB, Rizvi SI. Plant polyphenols as dietary antioxidants in human health and disease. Oxid Med Cell Longev 2009; 2:270-8.

29. Kuriyama S, Shimazu T, Ohmori K, Kikuchi N, Nakaya N, Nishino Y, et al. Green tea consumption and mortality due to cardiovascular disease, cancer, and all causes in Japan: the Ohsaki study. JAMA 2006; 296:1255-65. 
30. Perron NR, García CR, Pinzón JR, Chaur MN, Brumaghim JL. Antioxidant and prooxidant effects of polyphenol compounds on copper-mediated DNA damage. J Inorg Biochem 2011; 105:745-53.

31. Perron NR, Brumaghim JL. A review of the antioxidant mechanisms of polyphenol compounds related to iron binding. Cell Biochem Biophys 2009; 53:75-100.

32. Vauzour D, Rodriguez-Mateos A, Corona G, Oruna-Concha MJ, Spencer JP. Polyphenols and human health: prevention of disease and mechanisms of action. Nutrients 2010; 2:1106-31.

33. Dastmalchi K, Dorman HJD, Oinonen PP, Darwis Y, Laakso I, Hiltunen R. Chemical composition and in vitro antioxidative activity of a lemon balm (Melissa officinalis L.) extract. Lebensm Wissen Tecnol 2000; 41:391-400.

34. Youdim KA, Shukitt-Hale B, MacKinnon S, Kalt W, Joseph JA. Polyphenolics enhance red blood cell resistance to oxidative stress: in vitro and in vivo. Biochim Biophys Acta 2000; 1523:117-22.

35. Song G, Ouyang G, Bao S. The activation of Akt/PKB signaling pathway and cell survival. J Cell Mol Med 2005; 9:59-71.

36. Li Z, Dong X, Liu H, Chen X, Shi H, Fan Y, et al. Astaxanthin protects ARPE-19 cells from oxidative stress via upregulation of Nrf2-regulated phase II enzymes through activation of PI3K/Akt. Mol Vis 2013; 19:1656-66. 